\title{
Study on professional development of foreign language teacher in cross-cultural communication teaching
}

\author{
Yao Wang \\ Qilu Normal University, Ji'nan 250013, China
}

\begin{abstract}
Keywords: cross-cultural communication teaching; foreign language teacher; professional development; current situation; problem; effective promotion approach
\end{abstract}

\begin{abstract}
Chinese foreign language teachers seems especially important. This paper first presents basic connotation of professional development of foreign language teachers, then carefully analyzes current situation and various problems of professional development of Chinese foreign language teachers and finally proposes some effective approaches to promote professional development of foreign language teachers in combination of actual situations of Chinese foreign language teachers in cross-cultural communication teaching so as to make foreign language teachers really own, coordinate and share precious professional development experience.
\end{abstract}

\section{Professional status of foreign language teachers and their professional development}

The discussions on professional status of foreign language teachers have existed for a long time. Although many scholars disagree language teaching of foreign language teachers is professional teaching, they consistently admit foreign language teaching imposes large effects and functions on other courses and can also trigger the public to cognize the importance of language study. In recent years, many language teachers and language teaching institutions have focused on this issue again. Although there is still no universal approval, professional status of foreign language teachers is continuously being demonstrated. In the end, many consider language teaching also should be confirmed with other traditional professional occupations so as to provide possibility for establishing professional status of foreign language teachers.

Now that professional status of foreign language teachers has been established, what's the connotation of their professional development? Before disusing this basic connotation, we should first know the significance of teachers' professional development. The connotation of teachers' professional development is rich and diversified. Even so, the concept of teachers' professional development contains teachers' professional growth process explained from psychological perspectives and from the perspective of receiving education. Generally, teachers' professional development refers to a dynamic development process of continuously updating and perfecting teachers' professional development or internal professional structure and professional quality. In fact, professional development of foreign language teachers is basically similar to general teachers' professional development. The changes of foreign language teachers as language teachers mainly include ideological changes. The changes are progressive or inconspicuous. Some changes can be quantified. Closeness and openness of changes coexist. In a sense, professional development of foreign language teachers has certain innovative significance and value. We can deeply and thoroughly analyze and explain basic connotation of professional development under the precondition of establishing professional status of foreign language teachers. In general, we should carefully sort the connotation of professional development of foreign language teachers from two dimensions. The first dimension refers to psychological growth process of foreign language teachers in their professional teaching career. Specifically, it refers to enhancement of teachers' professional confidence, attitude and values, continuous update of subject knowledge and ability as well as improvement of professional teaching knowledge and ability. The second dimension refers to teachers' development in education and training aspects. 


\section{Current situation of problems of professional development of foreign language teachers in cross-cultural communication teaching}

In cross-cultural communication teaching, professional development status of Chinese foreign language teachers is not optimistic. Many problems need solving urgently.

(1) The depth and breadth of culture teaching ability are seriously insufficient. In cross-cultural communication teaching process, professional development of foreign language teachers is mainly intellectual development. Intellectual development mainly means foreign language teachers can overall arrange and guide culture teaching ability according to diverse latitudes of different cultures. Our findings show in cross-cultural communication teaching process, culture teaching ability of foreign language teachers is deficient. They are often caught in two extremes. One extreme considers the concept of culture in cross-cultural communication teaching refers to different local customs and practices of each country etc. The other extreme holds that culture is a very complex and abstract social phenomenon and very difficult to comprehend thoroughly. In fact, the first extreme means intellectual breadth is insufficient in professional development of foreign language teachers. It unilaterally understands simple superposition of cultural knowledge segment can form culture system. The second extreme reflects intellectual depth is insufficient in professional development of foreign language teachers. It indulges the concept of culture in empty talk, violates original intention of cross-cultural communication teaching and cannot really cultivate students' practical cultural exchange ability. Besides, it will give rise to limited culture teaching ability of foreign language teachers. The two extremes will cause that students misunderstand culture teaching in actual study, or memorize mechanically all kinds of cultural knowledge or mechanically understand empty and unmeaning concepts of culture. This obviously limits students to form and develop their critical thinking. Thus, they cannot boldly express and rethink their cultural behaviors and cultural values in cross-cultural communication teaching. Thus, cross-cultural communication teaching becomes insignificant and worthless.

(2) Teaching motivation development still lacks necessary systematicness and comprehensiveness. In cross-cultural communication teaching process, teaching motivation of foreign language teachers fail to jump from exam-oriented education. There is short of necessary systematicness and comprehensiveness. In fact, teaching motivation of foreign language teachers can be basically interpreted as psychological dynamics to drive them to take active part in teaching activities from the level of its features and functions. It will activate, maintain and adjust teachers' teaching activities. However, current exam-oriented education atmosphere is still not eliminated completely. In cross-cultural communication teaching process, teaching motivation of foreign language teachers still fail to adapt. Many foreign language teachers consciously or unconsciously discuss cultural topics with students according to their own interests in teaching process, or assign some cultural topics to students according to class hours. They do not formulate a systematical culture teaching plan or task and lack necessary systematicness. Thus, Chinese foreign language teachers lack real culture teaching motivation in cross-cultural communication teaching.

(3) There is short of teaching applicability and program. In cross-cultural communication teaching process, foreign language teachers fail to fully cultivate and improve students' cross-cultural communication awareness and ability. There is mainly short of necessary practical applicability. Many foreign language teachers are fuzzy about what should to and how to do in cross-cultural communication teaching process, so they cannot conduct procedural cross-cultural communication teaching. According to a survey, many foreign language teachers have more or less problems in culture teaching activities and teaching practice. Many foreign language teachers seldom mention the topics related to English culture. This fully shows Chinese foreign language teachers rarely or do not involve the basic level of culture concept in cross-cultural communication teaching. They mostly explain cultural knowledge unilaterally. Many foreign language teachers utilize advanced multimedia teaching means, but they are still limited to surface teaching level of cultural knowledge, and fail to deeply and thoroughly explain cultural value ideas. So, such static culture teaching mode cannot make students have comprehensive and dynamic understanding and cognition of the concept of culture, let alone improve students' cross-cultural communication 
awareness and ability. In other words, in cross-cultural communication teaching, foreign language teachers lack cultivation and improvement of students' culture application ability.

(4) There is short of diversified teaching awareness and behavior for students' plasticity. In professional development of foreign language teachers, oneness feature shows in cross-cultural communication teaching. Thus, foreign language teachers cannot adapt students' different individual needs in knowledge, practice and attitude in cross-cultural communication teaching, so it is very difficult to cultivate culture consciousness and cultural behavior subject with individual features. Although many foreign language teachers know this truth, they still do not pay attention to students' individual differences in culture teaching practice, but still adopt cultural contrast as well as other teaching skills and methods. Thus, it is hard for students to form cultural communication awareness or students have formed a mindset. They will mechanically communicate in actual cultural exchange process and cannot carry out correct cultural communication. This actually is profoundly influenced by Chinese exam-oriented education. Many foreign language teachers neglect guidance of students in cultural value and phenomenon cognition so that students present machine-made culture consciousness and behavior. This seriously obliterates students' due individual differences and finally causes that students' cultural exchange awareness is weak and their cultural communication ability is poor.

\section{Effective methods to promote professional development of foreign language teachers in cross-cultural communication teaching}

In Chinese cross-cultural communication teaching, effective methods to promote professional development of foreign language teachers refer to existing foreign teaching modes. This to some extents promotes professional development of Chinese foreign language teachers, but the methods lack originality and nativeness. There are great differences with actual teaching environment and teacher management system. So, we must review professional development of foreign language teachers, rethink teaching methods of foreign language teachers from voluntary and equal perspective so as to apply better teaching modes in cross-cultural communication teaching, better promote teachers' professional development in culture teaching and become high-quality foreign language teachers. We synthesize multiple culture teaching modes and try to give some constructive methods to facilitate professional development through the following aspects.

(1) Build teaching groups and carry out interactive and reflective teaching. Foreign language teachers should actively organize a group with grade as the unit in cross-cultural communication teaching, set up a special group leader and let the group leader lead members to discuss culture teaching contents. Such discussion should be conducted before each semester begins. Under the background of collective discussion, it is required to formulate culture teaching topics adapting students' culture study features, and rationally assign main teacher preparing lessons for each unit and specific unit teaching progress etc. Such cooperative group should gradually form key teaching points and difficult points. It is also required to confirm main teaching knowledge points and education points so that students an gain more cultural knowledge through some classroom teaching links and training activities. Of course, teaching methods of foreign language teachers and students' learning methods are also the content of collection lesson preparation. The teachers preparing lessons should form correlated and interactive favorable lesson preparation relationship, continuously rethink their teaching shortcomings, learn and refer to others' advantages so as to gradually perfect their teaching contents and improve their teaching level. Of course, foreign language teachers can boost their teaching level through mutual guidance and reflective teaching.

(2) Perfect teacher management mechanism and enhance teaching team building. Chinese foreign language teacher management mechanism still has many shortcomings. We must adjust and perfect it in time. To be more specific, we should give personnel management system certain flexible space, provide good environment for teachers' personal development, perfect teacher evaluation mechanism and guarantee system, give teachers sufficient professional autonomous right, encourage them to adopt teaching methods and modes with personalized features in cross-cultural communication teaching process and cultivate foreign language teaching personnel with innovation 
spirit and practical ability. Moreover, we should attach importance to self-development of foreign language teachers, let teachers integrate multiple roles and become teaching program makers, executors, evaluators and feedback providers. This requires use enhancing foreign language teaching team building, actively guide foreign language teachers to transform their identity and role in cross-cultural communication teaching, strive to cultivate personalized foreign language teachers and strengthen their teaching flexibility and innovation. Of course, we must carry out professional development of foreign language teachers according to their age and stages, cultivate their lifelong learning development concept, update their knowledge in time according to changes in external environment, adjust themselves in good time and achieve continuous self-development. Generally, foreign language teaching team building is achieved mainly through two approaches: internal training; external study. The former means we should organize related teacher training institutions or set up teacher training courses to regularly train foreign language teachers. The latte means to create conditions for foreign language teachers to further their studies overseas, consider fairness and multiple layers so as to cultivate more high-quality foreign language teachers for Chinese cross-cultural communication teaching.

\section{References:}

[1] Wu Shuli, Zhou Liying, An investigation of current situation of cross-cultural communication teaching in college English major [J]. Foreign Language Education in China, 2010(3)

[2] Wu Yian' exploration of professional development of foreign language teachers [J]. Foreign Languages Research, 2008(3)

[3] Zhong Qiquan, Teacher "professionalization": connotation and topic [A]. Zhang Weiyi, Teachers' education - hot issue on reform and development [C]. Nanjing: Nanjing Normal University Press, 2000

[4] ZhounYi, Xu Shijing, Jonathan Bailey, Cross-cultural ability and English teaching in China [A]. Jin Lixian, Martin Cortazzi. Study on learning culture of Chinese students: skill, awareness and cross-cultural adaptation [C]. Beijing: Foreign Language Teaching and Research Press, 2012 